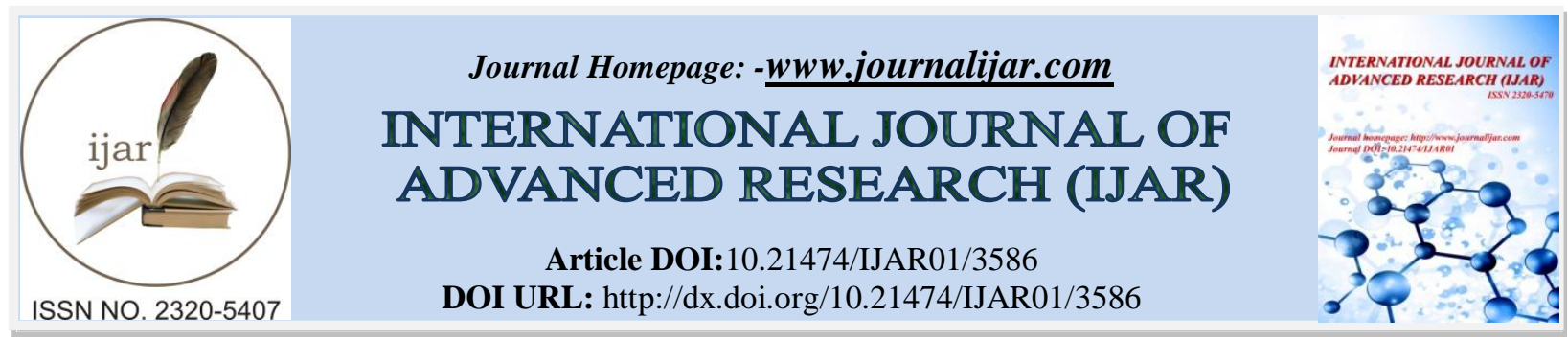

RESEARCH ARTICLE

\title{
USE OF CACTUS OPUNTIA AS A NATURAL COAGULANT: WATER TREATMENT IN DEVELOPING COUNTRIES.
}

\section{Ayub Karanja ${ }^{1}$, Li Fengting ${ }^{2}$ and Wilson Ng'ang' ${ }^{3}$.}

1. UNEP- Tongji Institute of Environment for Sustainable Development, College of Environmental Science and Engineering, Tongji University Shanghai. 20092, China.

2. UNEP-TONGJI Institute of Environment for Sustainable Development, College of Environmental Sciences and Engineering, State Key Laboratory of Pollution Control and Resource Reuse, Tongji University, Shanghai, P. R. China.

3. Faculty of Education Science, Biomedical Science. Egerton University.

\section{Manuscript Info}

Manuscript History

Received: 04 January 2017

Final Accepted: 08 February 2017

Published: March 2017

Key words:-

Chemical and natural coagulants; $\mathrm{pH}$; Cactus; Turbidity; Coagulationflocculation

\begin{abstract}
Observing the need for clean water and recycling of wastewater through effective treatment to help counter the continued water scarcity facing Kenya, the study sought to explore the possibility of using cactus in the coagulation-flocculation process. The study employed an analytic literature review model, sourcing recent and authoritative studies to investigate the effectiveness of cactus plants as coagulants, and the involved $\mathrm{pH}$ implications. The findings indicate that plantbased coagulants such as cactus are being considered as alternatives to conventional synthetic chemical coagulants in aspects such as costs, health effects, non-biodegradability, altered $\mathrm{pH}$ in post-treatment water and corrosion and transmission problems. In addition, cactus appears to have no significant effects on the $\mathrm{pH}$ of treated water. However, the findings demonstrate a lack of consensus regarding the optimal $\mathrm{pH}$ at which cactus is best effective in coagulation.
\end{abstract}

Copy Right, IJAR, 2017,. All rights reserved.

\section{Acronyms:-}

NTU Nephelometric Turbidity Meter

UPC Platinum- Cobalt Unit

STD Total Dissolved Solids

COD Chemical Oxygen demand

PAC Polyaluminium chloride

\section{Introduction:-}

Today's rapidly growing populations outstrip available water resources, which is especially problematic in developing countries that may be on the verge of water scarcity. In the context of limited water resources and water scarcity, water treatment and recycling procedures constitute one of the alternatives to obtain potable water in future. It is therefore necessary to develop suitable, rapid, and inexpensive water and wastewater treatment methods to remove turbidity, coloration, and heavy metals among other contaminants(Gupta et al. 2012). Such an approach to water treatment should also take into consideration contributions to environment and sustainable development. Wastewater treatment primarily entails the coagulation-flocculation process, which is a widely employed

Corresponding Author:- Ayub Karanja.

Address:- UNEP- Tongji Institute of Environment for Sustainable Development, College of Environmental 884 
physicochemical treatment approach. Traditionally, synthetic inorganic chemicals such as alum and ferric chloride have found wide used as coagulants and flocculants (Nilsen et al., 2005). However, the use of such conventional synthetic chemical coagulants raises environmental, safety, and sustainability concerns, surrounding aspects such as high procurement costs, possible human health risk concerns, their effects on the final $\mathrm{pH}$ of the treated water, and non-biodegradability which have detrimental environmental concerns (Yin 2010). These issues have led to the pursuit of alternative coagulants in wastewater treatment, with plant-based coagulants emerging as potential replacements. Such natural coagulants bear much promise in delivering effective wastewater treatment while responding to environmental and sustainability considerations.

In the Kenyan context, wastewater treatment is pertinent because the country has a water scarcity problem, with over $80 \%$ of its land considered arid and semi-arid (Patel, 2013). The country has a freshwater per capita of only $647 \mathrm{~m}^{3}$, which is well below the United Nations' recommended minimum $\left(1,000 \mathrm{~m}^{3}\right)$, with projections indicating a possible decline to $235 \mathrm{~m}^{3}$ by 2025 . As a case example, water supply to Nairobi stands at $580,000 \mathrm{~m}^{3} /$ day compared to a demand of $750,000 \mathrm{~m}^{3} /$ day, underscoring the necessity of sustained huge investments to expand water supply. In a scenario in which $20 \%$ of water supplied to the city ends up as wastewater, the wastewater volume may increase from $116,000 \mathrm{~m}^{3} /$ day to $172,000 \mathrm{~m}^{3} /$ day by the year 2017 , and $600,000 \mathrm{~m}^{3} /$ day by 2035 , an amount which is equivalent to the total water supplied in 2013 (Patel, 2013). These observations demonstrate that wastewater treatment constitutes an important potential source of water to relieve the water scarcity in Kenya. However, urban municipalities currently rely heavily on conventional treatment plants, which not only have the earlier mentioned demerits, but are also inadequate, non-functional at times due to technical hitches, or entirely lacking owing to associated operational costs and capital investments (Opaa\&Omondi, 2012). Such observations indicate the need for alternative coagulants in Kenya to address the weaknesses of conventional wastewater treatment to meet the water supply needs of the country.

In terms of environment and sustainability considerations, Kenya seeks to make progress on the 17 Sustainable Development Goals contained in the United Nation's 2030 Agenda (United Nations Development Programme, 2017). Pursuing alternative, natural, and effective coagulants contributes directly to one of these sustainable development goals and indirectly to a number of the other goals. In this case, goal 7 of the 2030 Agenda is to "ensure availability and sustainable management of water and sanitation for all" (Kimani, 2016). As a result, securing a locally available and inexpensive plant-based coagulant would help Kenya take significant steps towards the 2030 Agenda in the aspect of sustainable management of water and sanitation. Other goals to which alternative natural coagulants are relevant include goal 3, concerning healthy lives and wellbeing of all, goal 1 (poverty), goal 3 (improved nutrition and sustainable agriculture, and goal 10 (addressing inequality).

The possibility of using plant-based coagulants in treating wastewater would prove useful for the country in terms of such environmental, health, and sustainable development objectives, as these coagulants are generally considered to be safe to human health, inexpensive and locally available therefore affordable, biodegradable and result in lowlevel sludge production (Vijayaraghavan et al., 2011). One such plant-based coagulant under research entails the use of cactus species, with multiple studies seeking to establish the plant's effectiveness as a coagulant. Cactus is native to Kenya making it readily available, which indicates that it bears significant promise as a natural coagulant to address the problem faced in potable water supply and sustainable wastewater treatment in the country. However, its use as a coagulant first requires an overview of its effectiveness levels and optimum conditions especially in relation to $\mathrm{pH}$, which would then guide further research and use in local contexts in Kenya.

The objective of this paper is to review available scholarly work on the possible use of the cactus as an alternative coagulant through consolidating the available published literature concerning cactus' effectiveness in water treatment. The review is expected to avail information that can be useful to develop infrastructure for affordable and sustainable potable water provision in rural areas and informal sector communities of Kenya. The review will also offer technical know-how to informal settlement dwellers on the use of cactus to treat their wastewater for re-use.

\section{Literature Review:-}

The review of literature involved an analysis of published studies regarding the use of cactus-based coagulants published within the last 10 years to ensure that the insights are current and up-to-date. The review commences with studies that took some interest in the relevance of natural, plant-based coagulants such as cactus in light of the merits of such bio-coagulants and demerits of conventional chemical treatment. The next section covers the use of cactus derivatives as coagulants in water treatment, exploring their effectiveness when compared to other bio-coagulants 
and conventional ones. The review then narrows to focus on studies that included investigations on the effects of $\mathrm{pH}$ on the effectiveness of treatment including the $\mathrm{pH}$ of the final treated water when using cactus-derived coagulants. The literature review concludes with an overview analysis of the findings from the scholarly.

\section{Opportunity for Use of Cactus as a Natural Coagulant:-}

According to Yin (2010), lack of proper and effective water treatment systems in rural areas of underdeveloped regions of the world necessitates the use of cost-effective point-of-use approaches. The study demonstrates how the opportunity for use of natural plant-based coagulants arises. Among the various point-of-use approaches, coagulation has found wide use in treating both surface water and industrial wastewater. Such wide application in the removal of dissolved chemicals and turbidity from water entails the use of conventional chemical-based coagulants, including alum $\left(\mathrm{Al}_{2}\left(\mathrm{SO}_{4}\right)_{3}\right.$, poly-aluminium chloride $(\mathrm{PAC})$ and ferric chloride $\left.(\mathrm{FeCl})_{3}\right)$ However, Yin (2010) notes that these conventional coagulants are associated with demerits such as ineffectiveness in lowtemperature water, high procurement costs, deleterious impacts on human health, production of large sludge volumes and significant effect on the $\mathrm{pH}$ of the treated water. Meanwhile, the study establishes that natural plantbased alternatives avert these shortcomings of conventional coagulants through their low cost as they are locally available, the unlikely effect on extreme $\mathrm{pH}$ changes and high biodegradability. This study demonstrates that cactus may be advantageous because it is not only effective, but also helps avoid the environmental impacts of synthetic coagulants, besides also providing a sustainable option towards wastewater treatment.

Feria-Díazet al (2016) make similar observations regarding the use of conventional chemical coagulants in treating surface water and wastewater. The scholars noted that such coagulants are based on inorganic salts or synthetic organic polymers, which do have various disadvantages including risk to human health, high cost, high sludge volume production, water temperature dependent and significant alteration of the treated water. Further, chemical coagulants lead to high aluminum concentration in water after treatment, which interferes with water disinfection, which poses some distribution problems, decreases transmission capacity, and generates corrosion problems. Meanwhile, the scholars noted that alternative coagulants from natural sources have advantages in their safety for human health, biodegradability, low acquisition costs, low toxicity, and low-level sludge production. These merits underscore the environmental and sustainability gains that would be made upon embracing natural coagulants in treating wastewater. The study concludes that natural coagulants are equally effective in treating water and are also unlikely to alter the $\mathrm{pH}$ of treated water.

Vijayaraghavan et al. (2011) reviewed the use of plant-based coagulants in the treatment of water and wastewater. Among the factors contributing to the interest in the use of plant-based coagulants, the scholars highlight the presence of residual monomers during the use of synthetic polymers, which are undesirable owing to their neurotoxicity and carcinogenic properties. This led to researchers getting interested in plant-based coagulants, which could solve the problem of residual monomers. The plant-based coagulants are designed as point-of-use technologies in less-developed societies, as they are relatively cost-effective when compared to their chemical counterparts. In addition, the scholars note that plant-based coagulants are also advantageous owing to the ease of processing to useable form alongside their biodegradability, translating to sustainable wastewater treatment. These bio-coagulants achieve comparable treatment efficiency to chemical coagulants when employed in treating waters that have a low-to-medium turbidity range of 50-500 NTU. Although the scholars observed that application of the natural coagulants in industrial wastewater treatment is still in infancy, they noted that such coagulants hold much technical promise in water treatment. Cactus, Nirmali seeds (Strychnos potatorum), tannin, and Moringa oleifera are among the most studied plant-based coagulants, representing important progress in sustainable water treatment technologies.

\section{Cactus Use in Coagulation:-}

Several studies demonstrate that cactus is potentially an effective natural coagulant that is also responsive to environmental and sustainability concerns. Betatacheet al. (2014) compared north Algerian prickly pear cactus (Opuntia ficusIndica) juice with polyelectrolytes (Chimfloc C4346, Sedipur NF 102, a cationic polymer, and Sedipu AF 400) and inorganic conditioners $\left(\mathrm{FeCl}_{3}\right.$ and $\left.\mathrm{Al}_{2}\left(\mathrm{SO}_{4}\right)_{3}\right)$ in coagulating wastewater sludge. The study entailed a chemical characterization of the cactus juice alongside conditioning of the sludge with the juice and comparison chemicals, with analysis involving Fourier Transform Infrared spectral analysis and photometry. The findings demonstrated that the juice from the cactus promoted the coagulation of almost all of sludge, enabling liquid and solid separating and easing filtration process. Further, residual turbidity, the specific resistance of filtration and dryness obtained were comparable to those of Chimfloc C4346, and significantly better than those of Sedipur AF400 
and the inorganic chemicals analyzed, with the optimum dosage for the cactus being $0.4 \mathrm{~g} \mathrm{~kg}-1$ of dry matter. These findings led these researchers to conclude that the juice from the prickly pear cactus could find use as a natural conditioner in treating sewage sludge.

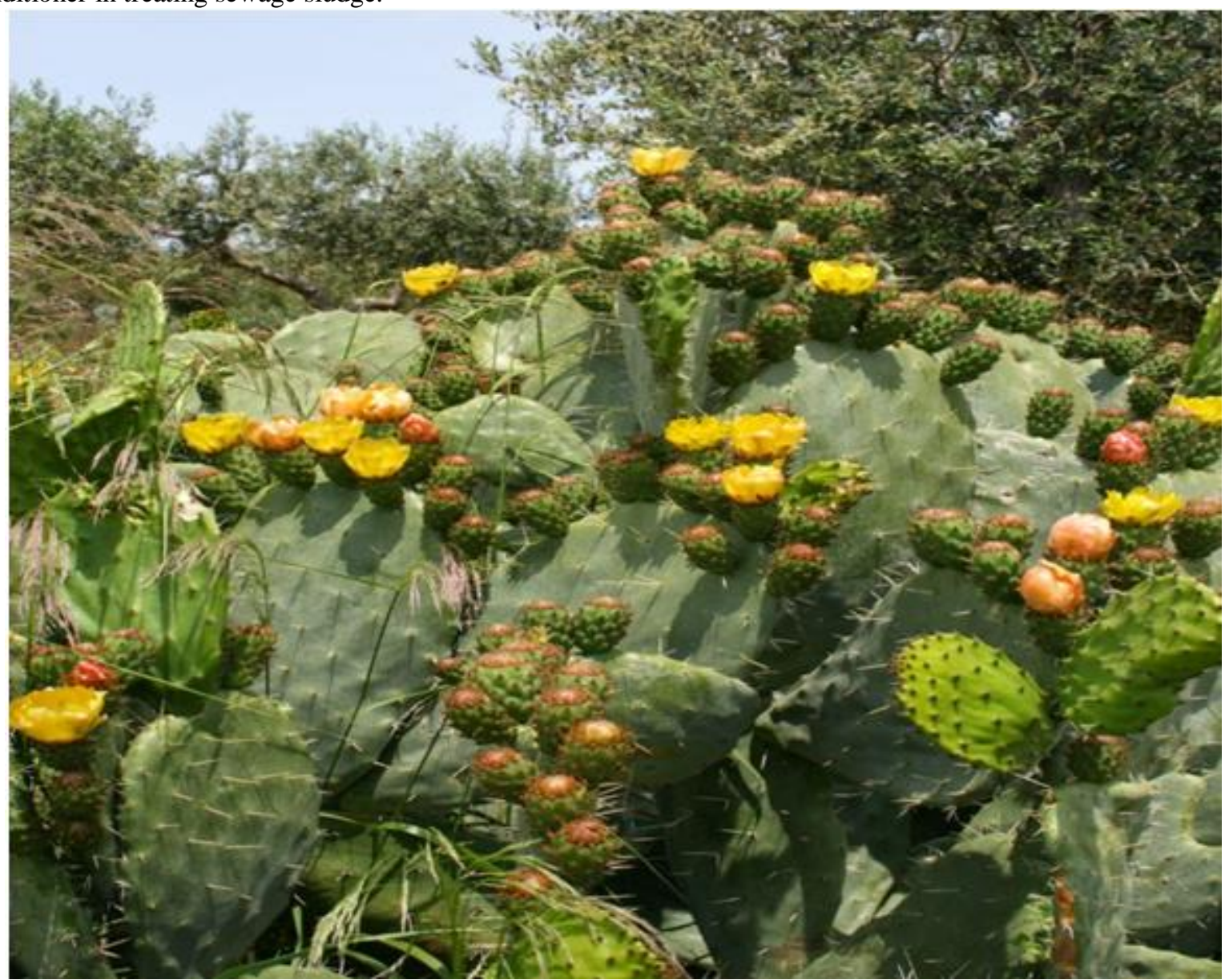

Fig. 1:- Cactus Opuntia (ficusindica).

Rodiño-Arguelloet al. (2015) compared five natural coagulants, Hylocereus cf. trigonus (cactus) stems, Campano (Albizia saman), exudate gum, the bark of Guácimo (Guazuma ulmifolia), and bark and seed from Moringa (Moringa oleifera) in treating raw water samples taken from Sinú river, Colombia. The scholars measured initial turbidity levels and turbidity removal efficiencies as a percent activity function for coagulant dosages at $5 \mathrm{mg} / \mathrm{L}$ to $200 \mathrm{mg} / \mathrm{L}$. Although the Moringa extract was found to be most effective in turbidity removal efficiency and coagulation activity, the cactus also had attractive results in removing turbidity (98\% turbidity removal). The aforementioned observations underscore the turbidity removal prospects of cactus extracts, demonstrating why it may find crucial use in wastewater treatment in the third world.

In another study, Fedalaet al. (2015) evaluated the performance of Opuntia ficus-indica as a flocculating agent. Collecting the cactus from Tipaza, Algeria, the scholars evaluated the coagulation-flocculation performance of the cactus and the quality of the treated water through measuring residual turbidity. After measuring the effectiveness of the cactus in coagulation at different solutions, the findings demonstrated that $0.2 \mathrm{mg} / \mathrm{L}$ cactus concentration was effective for the most turbid water, achieving best removal to $0.5 \mathrm{NTU}$. The residual turbidity levels were between 0.5 and $1.2 \mathrm{NTU}$, with the results being dependent on the initial turbidity of the water. These findings led the scholars to conclude that mucilage from $O$. ficus-indica is attractive as a natural material for water treatment technologies.

Nougbodéet al. (2013) also evaluated the properties of cactus as a natural coagulant for water clarification, using an aqueous Opuntia dillenii solution to clarify highly turbid surface water (turbidity varying from 418 NTU to 186 NTU). After undertaking flocculation and coagulation tests, the scholars found that Opuntia dillenii was useful for 
the treatment of highly turbid water. The solution had a removal efficiency varying from $89 \%$ to $93 \%$ for turbidity and suspended solids, as well as efficiency varying from $4 \%$ to $15 \%$ for obvious color using optimum values $1 \mathrm{~mL}$ to $10 \mathrm{~mL}$. Successive addition of the natural coagulant and lime resulted in an improved elimination of turbidity and suspended solids in the water alongside the improvement of color. Removal efficiency for turbidity and suspended solids reached over $95 \%$ while that for color was between $67 \%$ and $94 \%$. Such observations underscored the value of Opuntia dillenii in water clarification, with the scholars recommending that studies move beyond laboratory-scale settings.

Sellamiet al. (2014) compared the use of cactus juice as a bio-flocculant with conventional polyacrylamide in industrial wastewater treatment. The scholars conducted experiments in which they substituted polyacrylamide with cactus juice, noting the need to reduce the use of chemical products in coagulation. From the data collected, the scholars found that substituting polyacrylamide with cactus juice in coagulation-flocculation process was highly effective. The bio-flocculant had removal efficiencies of 59.1\%-69.1\% in removing chemical oxygen demand and $83.3 \%-88.7 \%$ in removing suspended solids. Upon addition of lime to the process, the removal efficiencies with cactus juice for both suspended solids and chemical oxygen demand improved to over $90 \%$. Based on these findings, they concluded that using cactus juice as flocculants meets sustainability requirements and is highly appropriate for regions in which cactuses grow naturally.

Pichleret al. (2012) studied the natural coagulants also through a comparison model, using mucilage from Opuntia ficusindica obtained from Tucson, Arizona against aluminum sulfate $\left(\mathrm{Al}_{2}\left(\mathrm{SO}_{4}\right)_{3}\right)$, the commonly used synthetic flocculant. After undertaking jar and cylinder experiments, the results demonstrated a high efficiency of the cactus mucilage in eliminating turbidity. At dosage concentrations of $3 \mathrm{mg} / \mathrm{L}$, the extract heightened particulate settling by $330 \%$ in comparison to aluminum sulfate. Meanwhile, its effectiveness was similar to that of the synthetic flocculants at $0.3 \%$ dosage of the necessary aluminum sulfate concentration. These findings led the scholars to conclude that cactus bears the potential of a 'green' coagulant that has the advantages of being environmentally friendly and inexpensive.

\section{Effectiveness and pH:-}

Yang et al. (2007) investigated the effectiveness of cactus Opuntia as a natural macromolecular coagulant in removing turbidity. The study involved a jar test technique, with the coagulant's effectiveness being reviewed on surface water (river and estuarine, 499 NTU and 547 NTU respectively) and landfill leachate. The scholars found that the coagulant reduced turbidity by as much as $98 \%$ in estuarine surface water and $70 \%$ in river water, but was less effective for leachate water $(31.6-41.9 \%)$. In terms of impacts on water $\mathrm{pH}$, the results indicated that increasing cactus dosage from 13 to $853 \mathrm{mg} / \mathrm{L}$ resulted in the marginal effect on the water's final $\mathrm{pH}$ (ranging from 7.25 to 7.69 for estuarine water and 7.83 to 8.49 for river water). These observations implied that substantial increases in dosage did not affect the final $\mathrm{pH}$ of the water compared to the effect of chemical-based coagulants.

Noting that natural coagulants provide benefits in local availability, affordability, and lesser health hazards, Mukhtaet al. (2015) evaluated the efficiency of turbidity removal of Opuntia stricta from Lahore, Punjab-Pakistan, as well as the effect of the water's pH on such efficiency. They assessed the effectiveness of this cactus species through measuring turbidity removal at various $\mathrm{pH}$ levels and coagulant doses. The findings demonstrated that Opuntia stricta, even when used at low doses, achieved residual turbidity levels of below 20 NTU. Unlike other coagulants that are highly $\mathrm{pH}$ dependent, the turbidity removal efficiency of cactus remained consistent across a wide range of $\mathrm{pH}$ levels (5 to 10). In addition, the scholars found that the $\mathrm{pH}$ of the water remained constant during the coagulation process, which means that $\mathrm{pH}$ adjustment may be unnecessary in treatment processes. Such a merit is crucial because post-treatment $\mathrm{pH}$ adjustments are often necessary when using metal coagulants.

Lozano et al. (2015) explored the efficiency of mucilage extracted from Opuntia ficus-indica (nopal) as a natural coagulant complementing aluminum sulfate in clarification of water obtained from river Magdalena, Colombia. The scholars employed the jar test method, considering factors such as proportion and concentration of the coagulants, $\mathrm{pH}$, and agitation speed in evaluating turbidity (NTU), color (UPC), and total dissolved solids. The study established that a maximum of $20 \%$ nopalmucilage coagulant proportion alongside agitation speeds of $200 \mathrm{rpm}$ reduced turbidity values to below $2 \mathrm{NTU}$, an efficiency corresponding to over 50\% (96-95\% highest). In addition, the combination reduced color to zero UPC and STD content to values under $200 \mathrm{mg} / \mathrm{L}$ without affecting the $\mathrm{pH}$ of the treated water significantly. These findings demonstrate that cactus mucilage can be used in combination with conventional coagulants to increase the efficiency of water treatment. 
Noting that natural coagulants promise advantages such as abundance, inexpensiveness, multifunction, and biodegradation, Shilpa et al. (2012) evaluated Opuntia ficusindica and hyacinth bean peels from Mysore, southern India in water treatment. After treating surface water with the two natural coagulants, they studied parameters such as turbidity, $\mathrm{pH}$, alkalinity, and bacterial contamination. The findings demonstrated that the turbidity removal effectiveness for the cactus was $89.03 \%$ at an optimum dosage of $20 \mathrm{mg} / \mathrm{L}$ while the percentage reduction in bacterial count was $20.15 \%$. A pH of 9 was also discovered to be the optimum level for effective water treatment when using this cactus species. These findings underscore the promise of cactus as a natural coagulant and alternative to synthetic chemical coagulants such as aluminum and iron salts.

Nharingo and Moyo (2016) explored the use of cactus-derived biomaterials in decontamination of wastewater, observing that the past decade had witnessed much interest into the biological material in environmental remediation. The two scholars undertook an analysis of literature covering aspects such as characterization, physicochemical compositions, application in bio-sorption and flocculation of pesticides, dyes, and metallic species. The studies reviewed provided findings based on different parts of the plant, including cladodes, fruit pulp, mucilage, and electrolytes. Their findings demonstrated that all these parts of the cactus had very high pollutant maximum sorption capacities, as well as removal ranging between $125.41000 \mathrm{mg} / \mathrm{g}$ and $0.312251 .56 \mathrm{mg} / \mathrm{g}$ for bio-sorption of dyes and metallic species. Cactus also had removal percentage ranges of $98.7 \%$ for turbidity, $93.62 \%$ of chemical oxygen and $100 \%$ for heavy metals. In addition, cactus biomaterials proved to have wide $\mathrm{pH}$ ranges $(3.27$ for fresh cladodes, 6.03 for mucilage powder, and 5.3-7.1 for the fruit pulp) in which they work efficiently. Ultimately, the cactus biomaterials proved effective in removing pollutants, leading the two scholars to recommend scaling up from laboratory settings to community pilot plants and at industrial levels.

Mouniret al. (2014) explored the flocculating activity of pectin and mucilage extracted from Opuntia ficusindica obtained from Pettit, Morocco. The tests were done on sanmix clay suspension, which served as synthetic turbid water. The findings demonstrated that the bio-flocculant had $98 \%$ flocculating activity in the sanmix clay suspension. In addition, the scholars found that the optimum dosage for mucilage was $2-8 \mathrm{~mL}$ while that of pectin was 2-6 mL by one-liter turbid water. In terms of $\mathrm{pH}$, the study established that flocculation activity was poor in strong alkali conditions than in acidic conditions, as demonstrated by less than $60 \%$ flocculation in $\mathrm{pH}$ of 10 and above. Flocculation activity was however higher in acidic conditions, peaking at $98.8 \%$ for pectin and $97.2 \%$ for mucilage at $\mathrm{pH}$ 3.0. As a result, the scholars noted that $\mathrm{pH}$ played a significant role in influencing the effectiveness of cactus-derived bio-flocculants.

Miller et al. (2008) quantitatively evaluated the coagulant properties of Opuntia spp., exploring its use as a coagulant for water treatment. The scholars undertook tests to evaluate the plant for turbidity removal in synthetic water samples (turbidity caused by kaolin clay particles), besides exploring some possible underlying coagulation mechanism for the plant. The findings indicated that the cactus species reduced turbidity in the water by $98 \%$ for a range of various turbidity levels, with such turbidity removal occurring at a $\mathrm{pH}$ of 10 . The scholars observed that such turbidity removal levels were similar to those established for Moringa oleifera, but noted that the cactus' turbidity removal occurred through a bridging coagulation mechanism. The scholars concluded that Opuntia spp. could find valuable use as part of point-of-use water treatment technology, offering a practical and affordable strategy to producing potable water in developing communities.

Noting the promise of Opuntia ficusindica as a cheap, locally abundant, and eco-friendly bio-flocculant, Nharingoet al. (2015) explored the effectiveness of cactus powder in bio-coagulation-flocculation of heavy metal ions from wastewater drawn from Mukuvisi River, Harare, Zimbabwe. At natural ionic strength and dosage of $8 \mathrm{mg} / \mathrm{L}$ alongside a floc settling time of $180 \mathrm{~min}$, the cactus powder achieved heavy metal removal of $84.16 \%(\mathrm{Cd}), 85.74 \%$ $(\mathrm{Zn}), 93.02 \%(\mathrm{Cu})$ and $100 \%(\mathrm{~Pb})$. The scholars also noted that the mechanism of the coagulation-flocculation process could have involved adsorption-bridging and adsorption-charge neutralization mechanisms. In terms of $\mathrm{pH}$, the scholars found that the process of coagulation-flocculation was optimum at $\mathrm{pH} 5$, with the percentage removal increasing gradually as $\mathrm{pH}$ increases up to $\mathrm{pH} 5$ and then decreasing beyond a $\mathrm{pH}$ of 8 . Based on these findings, the scholars concluded that the use of cactus powder in optimum conditions to remove heavy metal ions such as lead was highly promising and could be tested at commercial and industrial scales.

Another study by Bouatay and Mhenni (2014) involved effectiveness of cactus as an eco-friendly flocculant in the treatment of textile wastewater. Noting that Opuntia ficusindica mucilage bore promise owing to its abundance and inexpensiveness, the scholars reviewed its performance as a flocculant across parameters such as decolorization, 
turbidity abatement and COD removal. The findings demonstrated that a combination of cactus mucilage with aluminum sulfate was highly effective, with the best conditions for the flocculation process occurring at $\mathrm{pH} 7.25$, flocculant dosage of $40 \mathrm{mg} / \mathrm{L}$, mixing speed of $30 \mathrm{rpm}$ and a mixing time of 11 minutes. Based on these observed optimum conditions, the cactus mucilage yielded a decolorization of $99.84 \%$, turbidity abatement of $91.66 \%$ and COD removal of $88.76 \%$. Upon comparing flocculation performance of the cactus bio-flocculants agent and the commercial flocculants, the scholars found that the former exhibited the highest levels of pollution removal from wastewater.

Taa et al. (2016) explored the use of a cactus bio-flocculants extracted from Opuntia ficusindica in treating wastewater, basing their study on the need to replace chemical products and eliminate their negative effects on water disposal processes. The study entailed experiments using cactus juice on two types of wastewater, namely, synthetic chromium sulfate solution (100 ppm or $500 \mathrm{ppm})$ and real effluent obtained from a tannery (90 ppm or $900 \mathrm{ppm})$. From the findings, the scholars established that the cactus extracts facilitated rapid flocculation at a $\mathrm{pH}$ range of 7-9. In addition, the findings indicated that metal charge values were greatly reduced when cactus juice flocculation followed neutralization and lime coagulation. In this case, an initial charge of $176 \mathrm{mg} / \mathrm{l}$ reduced by $99.9 \%$ after 500 $\mathrm{ml}$ of $90 \mathrm{ppm}$ effluent was treated with $4 \mathrm{ml}$ cactus juice. In the same fashion, cactus juice treatment led to significant drop in chemical oxygen demand (94\%) and biological oxygen demand (95\%). In terms of the tannery effluent, at a concentration of $900 \mathrm{ppm}$, the cactus juice achieved a $98.6 \%$ turbidity reduction. Ultimately, the flocculation results from the two solutions were satisfying when compared to results from DKFLOC, the chemical flocculants.

\section{Overview of Literature Reviewed:-}

The literature reviewed demonstrates that opportunities for use of bio-coagulants are high because these coagulants solve some of the drawbacks of synthetic chemical-based coagulants. Here, bio-coagulants such as cactus have shown promise in averting the health effects caused by treatment of water and wastewater with chemical products. Besides being highly effective, they are inexpensive, environmentally benign and abundantly available. Such merits make bio-coagulants especially appealing in the context of the developing world regions where wastewater treatment is a significant challenge. Such effectiveness is evidenced in aspects such as reduction of turbidity, coloration, chemical oxygen demand and heavy metals among other parameters. However, the studies reviewed reveal diverse findings regarding aspects such as effectiveness levels and optimum conditions. For example, the studies provide varied results in aspects such as optimum dosage and concentration, mixing times and speeds and optimum $\mathrm{pH}$. Some studies demonstrate effectiveness at specific $\mathrm{pH}$ level while others demonstrate effectiveness over a wide range of $\mathrm{pH}$ levels. Most of the studies indicate that treatment with cactus-based bio-coagulants may not affect the final $\mathrm{pH}$ of the water. This diversity of insights from the literature and the lack of local studies in the context of Kenya underscore the need for localized research into the effectiveness of cactus-based bio-coagulants in treating wastewater in aspects such as turbidity, $\mathrm{pH}$, and COD before making recommendations.

\section{Methodology:-}

This study employed an extensive literature review to collect data on the need, use, and effectiveness of cactus as a coagulant. The studies included in the review were restricted to those published after 2005 to ensure up-to-date findings. Publications from peer-reviewed journals only were also targeted to ensure academic rigor. Identification and selection of relevant articles for use in the study entailed a search on Google Scholar with the search terms informed by the main areas of focus of the present study. The slashes indicate the use of related phrases or keywords to expand the literature search.

i. Use of natural/plant-based materials as coagulants in water and wastewater treatment

ii. The effectiveness of cactus/Opuntia ficusindica/Opuntia spp. as a coagulant in water/wastewater treatment

iii. Impacts on $\mathrm{pH}$ when using cactus/Opuntia ficusindica as a coagulant in water/wastewater treatment

Upon restricting the date, the initial search yielded 42 items published on the topic since 2005. Upon undertaking further screening to ensure the literature was restricted to those studies addressing strongly and specifically the topics of need, use, and effectiveness of cactus as a coagulant, the articles were reduced to 19. More than 19 articles are however cited in the present study owing to the use of other articles in the background section to help contextualize the research and provide a justification. Efforts were made to ensure rigor in these additional articles, restricting them to studies obtained from academic journals and important workshops or conferences on the wider and Kenyan context of wastewater treatment in particular. 


\section{Results and Discussion:-}

After an analysis of the literature, a number of emerging themes regarding the three main areas of focus that informed the literature search were established. Table 1 provides a summary of the main findings.

Table 1:- Summary of Key Findings on Use of Cactus as a Coagulant.

\begin{tabular}{|c|c|}
\hline $\begin{array}{l}\text { Opportunities for use of natural/plant-based } \\
\text { coagulants in water/wastewater treatment }\end{array}$ & Cited References \\
\hline $\begin{array}{l}\text { Lack of proper, effective, and sustainable water } \\
\text { treatment systems in rural or underdeveloped areas }\end{array}$ & Yin (2010) \\
\hline $\begin{array}{l}\text { Demerits of chemical coagulants: } \\
\text { - Ineffectiveness in low-temperature water, prohibitive } \\
\text { procurement costs } \\
\text { - Significant alteration of water pH, decreased } \\
\text { transmission capacity, and corrosion problems } \\
\text { - Environmental and sustainability issues: Negative } \\
\text { effects on human health, large sludge volumes, costs, } \\
\text { non-biodegradability }\end{array}$ & Yin (2010); Feria-Díazet al. (2016); Vijayaraghavan et al. (2011) \\
\hline $\begin{array}{l}\text { Merits of plant-based coagulants: } \\
\text { - Effectiveness aspects, no effect on } \mathrm{pH} \\
\text { - Environmental and sustainability aspects: Safe for } \\
\text { human health, biodegradability, inexpensive, low-level } \\
\text { sludge production }\end{array}$ & $\begin{array}{l}\text { Yin (2010); Feria-Díazet al. (2016); Vijayaraghavan et al. } \\
\text { (2011) }\end{array}$ \\
\hline \multicolumn{2}{|l|}{$\begin{array}{l}\text { Effectiveness of cactus/Opuntia ficusindica as a } \\
\text { coagulant }\end{array}$} \\
\hline Removal of turbidity & $\begin{array}{l}\text { Lozano et al. (2015); Betatacheet al. (2014); Rodiño-Arguelloet } \\
\text { al. (2015); Fedalaet al. (2015); Nougbodéet al. (2013); Pichler, } \\
\text { Young, and Alcantar's (2012); Shilpa et al. (2012); Yang et al. } \\
\text { (2007); Mukhtar et al. (2015); Nharingo and Moyo (2016); } \\
\text { Mouniret al. (2014); Miller et al. (2008) }\end{array}$ \\
\hline Removal of suspended solids & Nougbodéet al. (2013); Sellamiet al. (2014) \\
\hline Removal of dissolved solids & Lozano et al. (2015) \\
\hline Removal of chemical oxygen demand & $\begin{array}{l}\text { Sellamiet al. (2014); Taa et al. (2016); Bouatay and Mhenni } \\
\text { (2014); Nharingo and Moyo (2016) }\end{array}$ \\
\hline Removal of biological oxygen demand & Taa et al. (2016) \\
\hline Removal of color & $\begin{array}{l}\text { Lozano et al. (2015); Nougbodéet al. (2013); Bouatay and } \\
\text { Mhenni (2014); Nharingo and Moyo (2016) }\end{array}$ \\
\hline Removal of heavy metals & Nharingoet al. (2015); Nharingo and Moyo (2016) \\
\hline \multicolumn{2}{|l|}{ pH Implications } \\
\hline Little/marginal/no effect on final $\mathrm{pH}$ & Yang et al. (2007); Mukhtar et al. (2015); Lozano et al. (2015) \\
\hline Efficient removal over wide $\mathrm{pH}$ range & $\begin{array}{l}\text { Mukhtar et al. (2015); Nharingo and Moyo (2016); Taa et al. } \\
\text { (2016) }\end{array}$ \\
\hline Specific pH optimu & $\begin{array}{l}\text { Shilpa et al. (2012); Mouniret al. (2014); Miller et al. (2008); } \\
\text { Nharingoet al. (2015); Bouatay and Mhenni (2014) }\end{array}$ \\
\hline
\end{tabular}

\section{Use of Plant-Based Coagulants:-}

The literature reviewed reveals two main drivers behind the emergence of natural plant-based coagulants for water treatment, surrounding effectiveness, environmental, and sustainability considerations. The first driver entails the demerits associated with conventional chemical coagulants, which create an opportunity for consideration of their plant-based counterparts. Summing the demerits across the studies reviewed indicates that chemical coagulants are ineffective at low water temperatures, significantly alter water $\mathrm{pH}$, decrease transmission capacity, and cause corrosion problems, besides causing environmental and sustainable development concerns such as costliness, detriments to human health, non-biodegradability, and production of large sludge volumes (Yin, 2010; Feria-Diaz et al., 2016; Vijayaraghavan et al., 2011). The number and significance of disadvantages associated with synthetic chemical coagulants, especially considering the need for environmentally conscious and sustainable water treatment approaches in today's world, therefore have been a driving factor behind the emerging consideration of plant-based coagulants for use in water treatment. One study by Yin (2010) contextualizes the problem to developing world 
settings, where conventional water treatment may be insufficient or absent while at the same time proving too costly and environmentally undesirable.

The next significant driver for the use of plant-based coagulants is being necessitated by the merits presented by such coagulants, which are significant when juxtaposed against the drawbacks of chemical coagulants. The studies reviewed altogether indicate that plant-based coagulants are advantageous in aspects such as safety for human health, biodegradability, low cost acquisition, low-level sludge production, effectiveness in treating water, and no significant alteration $\mathrm{pH}$ of treated water (Yin, 2010; Feria-Diaz et al., 2016; Vijayaraghavan et al., 2011). Notably, most of the aforementioned merits indicate that plant-based coagulants such as cactus align with local, national, and global objectives in environmental protection and sustainable development. Such observations indicate that plantbased coagulants provide promising alternatives to synthetic chemicals commonly used in coagulation. In addition, the local availability noted in literature such as Yin (2010) also suggests that plant-based coagulants contribute to sustainable development of potable and wastewater treatment in underdeveloped regions of the world where there are challenges currently on treatment capacity. Such findings demonstrate the opportunities for rural and urban places in Kenya to explore the use of locally available plant-based coagulants.

\section{Effectiveness of Cactus as a Coagulant:-}

Besides its merits in promoting environmental and sustainable development concerns, the prospects of cactus in wastewater treatment in Kenya also centrally depends on its effectiveness as a coagulant. Narrowing down to the use of cactus in coagulation, evidence for removal of various contaminants and undesirable elements in wastewater varies. From the literature reviewed, there is overwhelming evidence regarding the effectiveness of the plant parts and extracts in the removal of turbidity, as demonstrated in the summary table (Table 2) indicating that twelve of the nineteen studied articles established such effectiveness. There is also some evidence for the effectiveness of cactus in removing chemical oxygen demand and coloration in wastewater from four studies for each of these parameters, which suggests that cactus may be useful in this respect. Meanwhile, removal of heavy metals (two studies), suspended solids (two studies), and dissolved solids (one study) indicates the need for more inquiry to establish sufficient evidence for the effectiveness of cactus in such respects. From these observations, the inference is that cactus has proven value in removing turbidity and significant evidence for removal of color and chemical oxygen demand, while removal of heavy metals, suspended solids, and dissolved solids still call for further research. Notably, the effectiveness of cactus in the aforementioned areas was influenced by the use of varying conditions in aspects such as $\mathrm{pH}$, optimum dosage, agitation speeds, and temperature. As a result, application of cactus in wastewater treatment in the Kenya context also necessitates studies to establish the optimal conditions within which the plant can be effective.

Table 2:- Evidence for the Effectiveness of Cactus in Wastewater Treatment.

\begin{tabular}{|c|c|}
\hline Contaminant Removed & Number of Supporting Studies \\
\hline Turbidity & 12 \\
\hline Suspended solids & 2 \\
\hline Dissolved solids & 1 \\
\hline Chemical oxygen demand & 4 \\
\hline Biological oxygen demand & 1 \\
\hline Color & 4 \\
\hline
\end{tabular}

\section{Implications for $\mathbf{p H}$ :-}

One determinant of the effectiveness of cactus as a coagulant is $\mathrm{pH}$ implications, where the $\mathrm{pH}$ of the treated water determines the value of cactus for coagulation. Besides, $\mathrm{pH}$ of water or wastewater being treated also constitutes a crucial consideration for optimal coagulation. In terms of effects on the final $\mathrm{pH}$, three studies reviewed reveal that cactus has little to no effect, which makes the treated water safe for use (Yang et al. 2007; Mukhtar et al., 2015; Lozano et al., 2015). These findings underscore the promise of cactus as a coagulant, especially considering that significant alteration of the $\mathrm{pH}$ of treated water is one of the demerits noted among synthetic chemicals commonly employed as coagulants.

The studies regarding the $\mathrm{pH}$ at which cactus is effective in the coagulation process provide diverging observations. On one hand, three studies reveal that the effectiveness of cactus in treating wastewater occurs across a wide range of pH values (Mukhtar et al., 2015; Nharingo\&Moyo, 2016; Taa et al., 2016). Meanwhile, five other studies indicate that the effectiveness of cactus in the coagulation process is determined by $\mathrm{pH}$, where the plant is effective within a 
narrow pH range (Shilpa et al., 2012; Mouniret al, 2014; Miller et al., 2008; Nharingoet al., 2015; Bouatay \& Mhenni, 2014). In addition, the values of $\mathrm{pH}$ given as optimal for effective coagulation vary among the studies. Shilpa et al. (2012) find cactus effective at an optimal pH of 9 for turbidity removal, Mouniret al. (2014) at pH 3.0 for turbidity removal, Miller et al. (2008) at pH 10, Nharingoet al. (2015) at pH 5 for heavy metal removal, and Bouatay and Mhenni (2014) at $\mathrm{pH} 7.25$ for removal of turbidity, color, and chemical oxygen demand. Such observations indicate that optimal $\mathrm{pH}$ may vary according to the contaminant being removed. At the same time, optimal $\mathrm{pH}$ may be varying because of the source and properties of the water, as well as the cactus species used in coagulation. Based on these observations, use of cactus in the Kenyan context may first require studies to establish effectiveness under various acidic or alkaline conditions using the Cactus specie that is native to the country.

\section{Conclusion:-}

The study sought to explore the promise of cactus as a natural plant-based coagulant for the environmentally friendly and sustainable treatment of water and wastewater, which would benefit developing world contexts such as Kenya. Following a review of the literature, the study establishes that plant-based coagulants offset the demerits associated with conventional chemical coagulants, while also being locally available. In this case, the pursuit of plant-based coagulants such as cactus is happening because such coagulants have the potential of not only being effective, but also allowing wastewater treatment that is sustainably manageable and environmentally appropriate. Such merits over traditional synthetic coagulants would be highly appropriate for the Kenyan context, helping to not only address water stress problems, but also deliver an approach aligned with Kenya's pursuit of sustainable development goals as set in the UN's 2030 Agenda. Cactus has been found to be effective in removal of turbidity, chemical oxygen demand, and coloration, with other possible uses being in the removal of heavy metals, suspended solids, and dissolved solids. The studies reviewed also showed that cactus has no significant effect on the $\mathrm{pH}$ of the treated water, unlike most synthetic chemical coagulants. However, there is no consensus regarding whether cactus is effective over a wide range of $\mathrm{pH}$ values or across a narrow range of $\mathrm{pH}$, as well as specific optimal $\mathrm{pH}$ for highest efficacy. Considering such effectiveness alongside the advantages in biodegradability, local availability, and lower costs, cactus potentially represents an environmentally friendly and sustainable solution for wastewater treatment in the Kenyan context. Further scholarship into cactus as a coagulant in the Kenyan context is necessary before a recommendation is made, where experimental models will help establish its effectiveness, optimal conditions, and cost-effectiveness for its successful use.

\section{References:-}

1. Aguilar, M. I., Sáez, J., Lloréns, M., Soler, A., Ortuno, J. F., Meseguer, V., \& Fuentes, A. (2005). Improvement of coagulation-flocculation process using anionic polyacrylamide as a coagulant aid. Chemosphere, 58(1), 4756.

2. Betatache, H., Aouabed, A., Drouiche, N., \&Lounici, H. (2014). Conditioning of sewage sludge by prickly pear cactus (Opuntia ficusIndica) juice. Ecological Engineering, 70, 465-469.

3. Bouatay, F., \& Mhenni, F. (2014). Use of the cactus cladodes mucilage (Opuntia ficusindica) as an eco-friendly flocculant: Process development and optimization using statistical analysis. International Journal of Environmental Research, 8(4), 1295-1308.

4. Fedala, N., Lounici, H., Drouiche, N., Mameri, N., \&Drouiche, M. (2015). Physical parameters affecting coagulation of turbid water with Opuntia ficus-indica cactus. Ecological Engineering, 77, 33-36.

5. Feria-Diaz, J. J., Rodiño-Arguello, J. P., \& Gutiérrez-Ribon, G. E. (2016). The behavior of turbidity, pH, alkalinity and color in Sinú River raw water treated by natural coagulants. RevistaFacultad de Ingeniería Universidad de Antioquia, 78, 119-128.

6. Gupta, V. K., Ali, I., Saleh, T. A., Nayak, A., \& Agarwal, S. (2012). Chemical treatment technologies for wastewater recycling - an overview. RSC Advances: An International Journal of Further the Chemical Sciences, 2(16), 6380-6388.

7. Kimani, B. (2016). Overview of the SDGs in Kenya. Ministry of Devolution and Planning. Retrieved from http://www.devolutionplanning.go.ke/images/Overview\%20of\%20the\%20SDGs\%20\%20in\%20Kenya.\%20Dia ni.pdf

8. Lozano, C. K. P., Mendoza, J., Aguas, Y., Salcedo Mendoza, G., Olivero Verbel, R., \& Mendoza Ortega, G. P. (2015). Nopal (Opuntia ficus-indica) as a complementary natural coagulant to clarify water. Producción+ Limpia, 10(1), 40-50. 
9. Miller, S. M., Fugate, E. J., Craver, V. O., Smith, J. A., \& Zimmerman, J. B. (2008). Toward understanding the efficacy and mechanism of Opuntia spp. as a natural coagulant for potential application in water treatment. Environmental Science \& Technology, 42(12), 4274-4279.

10. Mukhtar, A., Ali, W., \& Hussain, G. (2015). A preliminary study of Opuntia stricta as a coagulant for turbidity removal in surface waters. Proceedings of the Pakistan Academy of Sciences, 52(2), 117-124.

11. Mounir, B., Abdeljalil, Z., \& Abdellah, A. (2014). Comparison of the efficacy of two bio flocculants in water treatment. International Journal of Science, Engineering and Technology, 3(6), 734-737.

12. Nharingo, T., \&Moyo, M. (2016). Application of Opuntia ficus-indica in bioremediation of wastewaters: A critical review. Journal of Environmental Management, 166, 55-72.

13. Nharingo, T., Zivurawa, M. T., \&Guyo, U. (2015). Exploring the use of cactus Opuntia ficusindica in the biocoagulation-flocculation of $\mathrm{Pb}$ (II) ions from wastewaters. International Journal of Environmental Science and Technology, 12(12), 3791-3802.

14. Nougbodé, Y. A. E. I., Agbangnan, C. P., Koudoro, A. Y., Dèdjiho, C. A., Aïna, M. P., Mama, D., \&Sohounhloué, D. C. K. (2013). Evaluation of the Opuntia dillenii as a natural coagulant in water clarification: Case of treatment of highly turbid surface water. Journal of Water Resource and Protection, 5(12), 1242.

15. Opaa, B., \&Omondi, G. (2012). Wastewater production, treatment, and use in Kenya. Third Regional Workshop 'Safe Use of Wastewater in Agriculture,' 26-28 September 2012, Johannesburg, South Africa.

16. Patel, S. (2013). Wastewater management- Kenyan policy perspective and business perspective. 3rdAnnual Effluent and Water Management Conference, 5-6 December 2013, Laico Regency Hotel, Kenya.

17. Pichler, T., Young, K., \&Alcantar, N. (2012). Eliminating turbidity in drinking water using the mucilage of a common cactus. Water Science and Technology: Water Supply, 12(2), 179-186.

18. Rodiño-Arguello, J. P., Feria-Diaz, J. J., Paternina-Uribe, R. D. J., \&Marrugo-Negrete, J. L. (2015). Sinú River raw water treatment by natural coagulants. RevistaFacultad de Ingeniería Universidad de Antioquia, 76, 90-98.

19. Sellami, M., Zarai, Z., Khadhraoui, M., Jdidi, N., Leduc, R., \&Rebah, F. B. (2014). Cactus juice as bioflocculant in the coagulation-flocculation process for industrial wastewater treatment: A comparative study with polyacrylamide. Water Science and Technology, 70(7), 1175-1181.

20. Shilpaa, B. S., Akankshaa, K., \& Girish, P. (2012). Evaluation of cactus and hyacinth bean peels as natural coagulants. International Journal, 3(3), 187-191.

21. Taa, N., Benyahya, M., \&Chaouch, M. (2016). Using a bio-flocculent in the process of coagulation flocculation for optimizing the chromium removal from the polluted water. Journal of Materials and Environmental Science, 7(5), 1581-1588.

22. United Nations Development Program. (2017). A new sustainable development agenda. UNDP. Retrieved from http://www.ke.undp.org/content/kenya/en/home/post-2015.html

23. Vijayaraghavan, G., Sivakumar, T., \&Vimal Kumar, A. (2011). Application of plant based coagulants for wastewater treatment. International Journal of Advanced Engineering Research and Studies, 1(1), 88-92.

24. Yang, C., Suhaimi, A. T., Lim, Y. P., Mohd Safirun Nizan, I., Siti Nor Aisah, A. R., \& Ahmad Mahyuddin, M. M. (2007). Turbidity removal from surface water and landfill leachate using cactus Opuntia. Journal - The Institution of Engineers, Malaysia, 68(1), 61-64.

25. Yin, C. Y. (2010) Emerging usage of plant-based coagulants for water and wastewater treatment. Process Biochemistry, 45 (9), 1437-1444. 